\title{
Effect of Maternal Obesity on Foetal Growth and Metabolic Health of the Offspring
}

\author{
Claudio Maffeis Anita Morandi \\ Unit of Paediatric Diabetology, Clinical Nutrition and Obesity, University of Verona, \\ Verona, Italy
}

\author{
Key Words \\ Maternal obesity · Foetal growth · Metabolic health
}

\begin{abstract}
Maternal and placental conditions that are unfavourable for the embryo/foetus have longlasting effects on different tissues and functions of the body, which may persist for life and, potentially, also be transmitted to the offspring. This review resumes current evidence on principle maternal and gestational conditions associated with unfavourable metabolic programming of the offspring, along with their mechanisms of action, either supposed or already proved.

(C) 2017 The Author(s)

Published by S. Karger GmbH, Freiburg
\end{abstract}

\section{Introduction}

Obesity runs in families, suggesting that genes play a role in predisposing individuals to obesity: having one or both parents obese, especially the mother, increases the risk of obesity for the offspring $[1,2]$. Twin and adoption studies have demonstrated that genes largely contribute to the process leading to excess fat accumulation in the body [3, 4]. Nevertheless, the polygenic nature of the disease still hinders the identification of specific gene polymorphisms helpful in selecting subjects at a higher risk of becoming obese. In fact, recent genomewide analyses identified dozens of single genetic loci associated with obesity; but all these genes only account for a small percentage of obesity susceptibility $[5,6]$.

Although genes predispose an individual to become obese, environmental exposition to obesity risk factors is necessary for the expression of the obese phenotype. The importance

Prof. Dr. Claudio Maffeis

Unit of Paediatric Diabetology, Clinical Nutrition and Obesity

University of Verona

Via Bengasi, 4, 37134 Verona, Italy

claudio.maffeis@univr.it 
of being exposed to an obesogenic environment is supported by the world-wide increase in obesity that began in the 1980s (40\% in 30 years in adults), likely attributable to the rapid environmental and behavioural changes that occurred during this time frame more than to changes in genes.

The effects of environment begin early in life. The first environment to which the organism is exposed is the maternal womb. In the intra-uterine life, the organism is particularly sensitive to environment because of three main factors: i) the total dependency of the embryo and foetus on nutrients and oxygen supplies from the mother through the placental interface; ii) the high speed of anatomic and functional maturation of tissues and organs as well as of the metabolic regulation pathways; iii) the high developmental plasticity that allows tissue structure to adapt in response to environmental changes. This extremely sensitive status persists also in the first postnatal period and declines progressively with the infant's growth and adaptation to the new extra-uterine environment.

It is now believed that epigenetic mechanisms, in which environmental factors cause changes in gene expression, could help to explain the observed rapid increase in obesity prevalence [7]. The aim of this paper is to report the main evidence available on the relationship between maternal obesity as well as foetal growth and the metabolic health of the offspring.

\section{Developmental Programming}

Clear evidence is available that maternal and placental conditions unfavourable for the embryo/foetus may have long-lasting effects on different tissues and functions of the body, which may persist for life and, potentially, also be transmitted to the offspring [8, 9].

The term 'developmental programming' defines a set of mechanisms that lead to permanent changes in the physiology, metabolism and epigenome of an individual, which will subsequently increase his disease risk, as a consequence of having been exposed to risk factors during prenatal or early postnatal development [10]. These risk factors include, but are not limited to, maternal nutrition (under- or over-nutrition), teratogens (pollutants, drugs, alcohol etc.), altered hormonal milieus (resulting from maternal obesity, excess gestational weight gain, diabetes mellitus), maternal stress and oxidative stress (maternal hypertension or placenta insufficiency) [11]. The principal non-mutually exclusive mechanisms by which intrauterine exposures program offspring are: permanent structural changes of organs and tissues (pancreas, liver, skeletal muscle, adipose tissue, brain etc.), epigeneticprogramming of gene expression (by DNA methylation, histone modifications and microRNA) and accelerated cellular aging (by oxidative stress, inflammation and altered hormonal milieu) [12]. Interestingly, transgenerational heritability of epigenetic modifications is possible through modification of the epigenome of germ cells of the developing foetus [13].

\section{Prenatal and Perinatal Obesity-Sensitive Time Windows}

\section{Pre-Pregnancy Obesity}

Obesity at conception is already an obesity risk factor for the offspring. Studies in animals demonstrated that offspring born from gametes of obese mothers and fathers, fertilized in vitro and implanted in lean surrogate dams, have a high risk of developing obesity and insulin resistance in adult life [14]. Moreover, the effect of male and female gametes was additive in female but not in male offspring. Males had the highest risk of developing obesity if born from maternal gametes of obese mothers independent of obese or nonobese father gametes. Therefore, offspring of obese mothers, regardless of intrauterine life exposition to maternal 
Maffeis and Morandi: Effect of Maternal Obesity on Foetal Growth and Metabolic Health of the Offspring

obesity, have a higher risk of developing obesity than offspring of obese fathers. In humans, maternal gastrointestinal bypass surgery was able to prevent transmission of obesity to children born after surgery compared with children born from the same mother before surgery [15]. All these findings may be explained by epigenetic mechanisms.

\section{Gestational Weight Gain}

Excessive gestational weight gain is associated with an obesity risk in childhood [16]. The risk is high for a high weight gain in the first trimester of pregnancy (22\% of risk increase per $200 \mathrm{~g} /$ week of excessive gestational weight gain) [17]. In the second and third trimester of pregnancy, excessive weight gain is associated with a higher risk of bearing large-for-gestational-age neonates but not with child anthropometry at later ages. Interestingly, maternal weight gain and increased BMI between pregnancies increases the risk of overweight in offspring compared with their siblings [18].

Studies in animals have shown that maternal over-nutrition during pregnancy, both high-fat and high-calorie diets, increases adiposity and inflammation in the offspring [19]. Moreover, the offspring of dams exposed to a high-fat diet during pregnancy maintained an adverse metabolic profile and epigenetic changes through adulthood [20]. The mechanisms linking maternal malnutrition and excessive weight in pregnancy to later-life metabolic health of the offspring are unclear. Some evidence is available on the association between maternal diet and reduced leptin or insulin sensitivity as well as reduction of sympathetic activity within the adipose tissue of the offspring [21-23]. Leptin, insulin, glucocorticoids and ghrelin are involved in metabolic programming mechanisms at both central (CNS) and peripheral levels (adipose tissue, liver, skeletal muscle) [21, 22, 24].

\section{Body Fat and Metabolic Changes in Pregnancy}

Normal-weight and obese women tend to gain a similar amount of fat during pregnancy. However, lean women accumulate fat in the peripheral body compartments, whereas obese women store fat mainly in the abdominal area, with accumulation of fat also in the liver and placenta [25].

Body fat distribution in obese women favours lipotoxicity and metabolic dysfunctions, leading to foetal exposition to glucose and fat overload that promotes an increase in foetal size and fat mass as well as metabolic dysfunction and inflammation, which favours altered metabolic programming.

Glucose metabolism in pregnancy is characterized by increased insulin secretion in the first two trimesters, which promotes maternal body fat accumulation, and by insulin resistance in the last trimester, favouring a substrate supply to the foetus to satisfy the increased demand. The foetus uses more than $50 \%$ of the total maternal glucose turnover, which mainly depends on increased maternal hepatic gluconeogenesis. This process is exaggerated in pregnant women with obesity and/or diabetes, leading to glucose and lipid overload in the foetus. Dysfunctional maternal glucose metabolism in pregnancy is associated with the risk of obesity in the offspring. In particular, among women with gestational diabetes, maternal fasting plasma glucose during pregnancy was associated with birth size and the risk of obesity at the age of 7 years in their children, adjusting for pre-pregnancy BMI [26]. Exposure to intrauterine hyperglycaemia was associated with impaired insulin sensitivity and relatively impaired insulin secretion in adulthood, both of which are characteristics of type 2 diabetes [27]. 
Maffeis and Morandi: Effect of Maternal Obesity on Foetal Growth and Metabolic Health of the Offspring

\section{Pregnancy, Microbiome and Risk of Obesity in Offspring}

Mothers share their microbes and microbiome metabolites with the foetus during delivery and during lactation. However, it has recently been suggested that the womb may not be sterile and microbial exposure may begin in utero, so the placenta and amniotic fluid may be potential sources of intrauterine microbial transmission from the mother to the developing foetus [28]. Maternal diet, health status, metabolism, mode of delivery, gestational weight gain, genetics and use of antibiotics affect microbiome composition [29].

The maternal gut microbiota is different in normal-weight and obese pregnant women, particularly in the second half of pregnancy. Obese women showed an increase in Firmicutes phylum (Staphylococcus) and some Proteobacteria (Escherichia coli) [30]. Maternal microbes may affect the developing foetus through several mechanisms [31]. One of these is foetal exposition to elevated levels of microbe-derived plasma endotoxin, which may increase gut translocation of bacteria-derived products across the intestinal mucosa, contributing to systemic and placental inflammation and insulin resistance. Another possible consequence of nutrient-gut microbiota interaction is increased acetate production. This, by subsequent parasympathetic activation, has been shown to increase glucose-stimulated insulin secretion, ghrelin secretion, food intake and obesity in rats [32]. Indeed, further studies are necessary to confirm these interesting and stimulating preliminary findings.

From a clinical point of view, manipulation of microbiota by diet, antibiotics, pre-, pro- or synbiotics could potentially contribute to reduce the risk of developing obesity, especially if applied in specific high-sensitive windows, like pregnancy and early infancy. However, further experience must be accumulated in order to define the efficacy and safety of this approach for preventing obesity.

\section{Prevention of Maternal Obesity-Related Health Consequences for the Offspring}

Guidelines to prevent the offspring from developing negative health consequences associated with maternal obesity or with excessive gestational weight gain, have been available since 1990, have been revised in 2009 [33] and have been recently acknowledged by the European College of Obstetrics and Gynaecology [34]. These guidelines clearly state that obese women should try to lose weight and improve their lifestyle before conceiving and that different ranges of ideal gestational weight gain should be pursued by pregnant women according to their pregestational weight status [33]. In particular, while normal-weight women should gain 25-35 lbs (11.25-15.75 kg), overweight and obese ones should gain $15-25 \mathrm{lbs}(6.75-11.25 \mathrm{~kg})$ and $11-20 \mathrm{lbs}(4.95-9.00 \mathrm{~kg})$ respectively [33]. This objective should be achieved with the help of nutritional and lifestyle counselling from health professionals in charge of the follow-up of pregnant women [33]. Unfortunately, according to recent epidemiological data from the US, since the publication of the guidelines in 1990 no reduction in gestational weight gain among overweight/obese women relative to normal-weight/ underweight women and no changes in gestational weight gain by pre-pregnancy BMI for either overweight/obese or normal-weight/underweight women have occurred [35]. Moreover, randomized controlled trials targeting obese pregnant women failed to reduce their gestational weight gain [36]. Thus, the ideal weight management in obese pregnant women remains to be determined, and effective policies targeting maternal and child health via lifestyle and dietary behaviours are lacking [33-36]. 
Maffeis and Morandi: Effect of Maternal Obesity on Foetal Growth and Metabolic Health of the Offspring

\section{Conclusions}

Maternal obesity is a proven obesity risk factor for the offspring. The progressive trend of increasing obesity prevalence among pregnant women is alarming and suggests the need for further efforts in public health intervention for obesity control.

Available evidence strongly supports the rationale to begin obesity prevention as soon as possible. In particular, the crucial role of the mother suggests starting intervention before pregnancy and to continue prevention both during and after pregnancy.

At present, an adequate diet and physical activity before and during pregnancy as well as control of gestational weight gain and blood glucose are mandatory procedures to reduce the risk of obesity in offspring.

\section{Disclosure Statement}

The authors declare no conflict of interest.

\section{References}

1 Maffeis C, Micciolo R, Must A, Zaffanello M, Pinelli L: Parental and perinatal factors associated with childhood obesity in north-east Italy. Int J Obes Relat Metab Disord 1994;18:301-305.

2 Whitaker RC, Wright JA, Pepe MS, Seidel KD, Dietz WH: Predicting obesity in young adulthood from childhood and parental obesity. N Engl J Med 1997;337:869-873.

3 Stunkard AJ, Foch TT, Hrubec Z: A twin study of human obesity. JAMA 1986;256:51-54.

4 Silventoinen K, Rokholm B, Kaprio J, Sørensen TI: The genetic and environmental influences on childhood obesity: a systematic review of twin and adoption studies. Int J Obes (Lond) 2010;34:29-40.

5 Morandi A, Meyre D, Lobbens S, Kleinman K, Kaakinen M, Rifas-Shiman SL, Vatin V, Gaget S, Pouta A, Hartikainen AL, Laitinen J, Ruokonen A, Das S, Khan AA, Elliott P, Maffeis C, Gillman MW, Järvelin MR, Froguel P: Estimation of newborn risk for child or adolescent obesity: lessons from longitudinal birth cohorts. PLoS One 2012;7:e49919.

6 Albuquerque D, Stice E, Rodriguez-Lopez R, Manco L, Nobrega C: Current review of genetics of human obesity: from molecular mechanisms to an evolutionary perspective. Mol Gen Genomics 2015;290:1191-1221.

7 Deans C, Maggert KAQ: What do you mean 'Epigenetic'? Genetics 2015;199:887-896.

8 Ravelli RM, Stein ZA, Susser MW: Obesity in young men after famine exposure in utero and early infancy. N Engl J Med 1976;295:349-353.

9 Gluckman PD, Hanson MA, Cooper C, Thornburg KL: Effect of in utero and early-life conditions on adult health and disease. N Engl J Med 2008;359:61-73.

10 Waterland RA, Garza C: Potential mechanisms of metabolic imprinting that lead to chronic disease. Am J Clin Nutr 1999;69:179-197.

11 Waterland RA: Epigenetic mechanisms affecting regulation of energy balance: many questions, few answers. Annu Rev Nutr 2014;34:337-355.

12 Fernandez-Twinn DS, Constância M, Ozanne SE: Intergenerational epigenetic inheritance in models of developmental programming of adult disease. Semin Cell Dev Biol 2015;43:85-95.

13 Desai M, Jellyman JK, Ross MG: Epigenomics, gestational programming and risk of metbolic syndrome. Int J Obes 2015;39:633-641.

14 Huypens P, Sass S, Wu M, Dyckhoff D, Tschöp M, Theis F, Marschall S, Hrabě de Angelis M, Beckers J: Epigenetic germline inheritance of diet-induced obesity and insulin resistance. Nat Genet 2016;48:497-499.

15 Kral JG, Biron S, Simard S, Hould FS, Lebel S, Marceau S, Marceau P: Large maternal weight loss from obesity surgery prevents transmission of obesity to children who were followed for 2 to 18 years. Pediatrics 2006; 118:e1644-1649.

16 Fraser A, Tilling K, Macdonald-Wallis C, Sattar N, Brion MJ, Benfield L, Ness A, Deanfield J, Hingorani A, Nelson SM, Smith GD, Lawlor DA: Association of maternal weight gain in pregnancy with offspring obesity and metabolic and vascular traits in childhood. Circulation 2010;121:2557-2564.

17 Karachaliou M, Georgiou V, Roumeliotaki T, Chalkiadaki G, Daraki V, Koinaki S, Dermitzaki E, Sarri K, Vassilaki M, Kogevinas M, Oken E, Chatzi L: Association of trimester-specific gestational weight gain with fetal growth, offspring obesity, and cardiometabolic traits in early childhood. Am J Obstet Gynecol 2015;212:502.e1-14.

18 Alfaradhi MZ, Ozanne SE: Developmental programming in response to maternal overnutrition. Front Genet 2011;2:27. 
Maffeis and Morandi: Effect of Maternal Obesity on Foetal Growth and Metabolic Health of the Offspring

19 Sampey BP, Vanhoose AM, Winfield HM, Freemerman AJ, Muehlbauer MJ, Fueger PT, Newgard CB, Makowski L: Cafeteria diet is a robust model of human metabolic syndrome with liver and adipose inflammation: comparison to high-fat diet. Obesity (Silver Spring) 2011;19:1109-1117.

20 Marco A, Kisliouk T, Tabachnik T, Meiri N, Weller A: Overweight and CpG methylation of the Pomc promoter in offspring of high-fat-diet-fed dams are not 'reprogrammed' by regular chow diet in rats. FASEB J 2014;28: 4148-4157.

21 Férézou-Viala J, Roy AF, Sérougne C, Gripois D, Parquet M, Bailleux V, Gertler A, Delplanque B, Djiane J, Riottot M, Taouis M: Long-term consequences of maternal high-fat feeding on hypothalamic leptin sensitivity and diet-induced obesity in the offspring. Am J Physiol Regul Integr Comp Physiol 2007;293:R1056-1062.

22 Sanguinetti E, Liistro T, Mainardi M, Pardini S, Salvadori PA, Vannucci A, Burchielli S, Iozzo P: Maternal high-fat feeding leads to alterations of brain glucose metabolism in the offspring: positron emission tomography study in a porcine model. Diabetologia 2016;59:813-821.

23 Prior LJ, Davern PJ, Burke SL, Lim K, Armitage JA, Head GA: Exposure to a high-fat diet during development alters leptin and ghrelin sensitivity and elevates renal sympathetic nerve activity and arterial pressure in rabbits. Hypertension 2014;63:338-345.

24 Ramamoorthy TG, Begum G, Harno E, White A: Developmental programming of hypothalamic neuronal circuits: impact on energy balance control. Front Neurosci 2015;9:1-16.

25 Ehremberg HM, Huston-Presley L, Catalano PM: The influence of obesity and gestational diabetes mellitus on accretion and the distribution of adipose tissue in pregnancy. Am J Obstet Gynecol 2003;189:944-948.

26 Zhu Y, Olsen SF, Mendola P, Yeung EH, Vaag A, Bowers K, Liu A, Bao W, Li S, Madsen C, Grunnet LG, Granström C, Hansen S, Martin K, Chavarro JE, Hu FB, Langhoff-Roos J, Damm P, Zhang C: Growth and obesity through the first $7 \mathrm{y}$ of life in association with levels of maternal glycemia during pregnancy: a prospective cohort study. Am J Clin Nutr 2016;103:794-800.

27 Kelstrup L, Damm P, Mathiesen ER, Hansen T, Vaag AA, Pedersen O, Clausen TD: Insulin resistance and impaired pancreatic $\beta$-cell function in adult offspring of women with diabetes in pregnancy. J Clin Endocrinol Metab 2013;98:3793-3801.

28 Aagaard K, Ma J, Antony KM, Ganu R, Petrosino J, Versalovic J: The placenta harbors a unique microbiome. Sci Transl Med 2014;6:237ra65.

29 Kerr CA, Grice DM, Tran CD, Bauer DC, Li D, Hendry P, Hannan GN: Early life events influence whole-of-life metabolic health via gut microflora and gut permeability. Crit Rev Microbiol 2015;41:326-340.

30 Santacruz A, Collado MC, García-Valdés L, Segura MT, Martín-Lagos JA, Anjos T, Martí-Romero M, Lopez RM, Florido J, Campoy C, Sanz Y. Gut microbiota composition is associated with body weight, weight gain and biochemical parameters in pregnant women. Br J Nutr 2010;104:83-92.

31 Basu S, Haghiac M, Surace P, Challier JC, Guerre-Millo M, Singh K, Waters T, Minium J, Presley L, Catalano PM,Hauguel-de Mouzon S: Pregravid obesity associates with increased maternal endotoxemia and metabolic inflammation. Obesity (Silver Spring) 2011;19:476-482.

32 Perry RJ, Peng L, Barry NA, Cline GW, Zhang D, Cardone RL, Petersen KF, Kibbey RG, Goodman AL, Shulman GI: Acetate mediates a microbiome-brain- $\beta$-cell axis to promote metabolic syndrome. Nature 2016;534:213217.

33 National Academies of Science, Health and Medicine Division: Weight Gain During Pregnancy: Reexamining the Guidelines. 2009. http://nationalacademies.org/hmd/reports/2009/weight-gain-during-pregnancy-reexamining-the-guidelines.aspx (last accessed March 29, 2017).

34 Devlieger R, Benhalima K, Damm P, Van Assche A, Mathieu C, Mahmood T, Dunne F, Bogaerts A: Maternal obesity in Europe: where do we stand and how to move forward? A scientific paper commissioned by the European Board and College of Obstetrics and Gynaecology (EBCOG). Eur J Obstet Gynecol Reprod Biol 2016; 201:203-208.

35 Hamad R, Cohen AK, Rehkopf DH: Changing national guidelines is not enough: The impact of 1990 IOM recommendations on gestational weight gain among U.S. women. Int J Obes (Lond) 2016;40:1529-1534.

36 Flynn AC, Dalrymple K, Barr S, Poston L, Goff LM, Rogozińska E, et al: Dietary interventions in overweight and obese pregnant women: a systematic review of the content, delivery, and outcomes of randomized controlled trials. Nutr Rev 2016;74:312-328. 